\title{
Influence of Antibiotics and Surfactants Addition on Growth and Methionine Productivity by Bacillus cereus*
}

\author{
Kelechi Stanley Dike ${ }^{1 \#}$, Ikechukwu Amechi Ekwealor ${ }^{1}$, Samuel Chukwunyelum Eziuzor ${ }^{2}$ \\ ${ }^{1}$ Department of Applied Microbiology and Brewing, Nnamdi Azikiwe University Awka, Awka, Nigeria \\ ${ }^{2}$ Department of Biological Sciences, Aba Take-off Campus, Rhema University, Obeama-Asa, Nigeria \\ Email: "kekedyke2000@yahoo.com
}

Received June 19, 2012; revised August 15, 2012; accepted September 25, 2012

\begin{abstract}
The effects of antibiotics and surfactant addition on methionine accumulation in the broth culture of three strains of methionine yeilding Bacillus cereus (B. cereus DS-13, B. cereus AS-9 and B. cereus RS-16) recovered from different soil ecovars in Owerri Nigeria were investigated. Ampicillin and erythromycin neither stimulated growth nor enhanced methionine production in Bacillus cereus DS-13, while tetracycline and chloramphenicol stimulated growth and enhanced methionine yield in Bacillus cereus DS-13 and Bacillus cereus AS-9. Ampicllin had the highest stimulatory effect on growth and methionine production in Bacillus cereus RS 16. Tween 80 and palmitic acid stimulated growth and improved methionine accumulation in the broth culture of all Bacillus strains while stearic acid did not improve yield in all Bacillus strains.
\end{abstract}

Keywords: Methionine; Bacillus cereus; Fermentation; Antibiotics; Surfactants

\section{Introduction}

Methionine is an essential, economically important amino acid used as food and feed supplement. It is a precursor for the other sulfur amino acids, cysteine, taurine and glutathione, and plays an important role in human body by assisting in the breakdown of fats and preventing fat build up in the liver and arteries [1,2]. Methionine is essential for the absorption, transportation and availability of selenium and zinc in cellular functions. It helps in the excretion of cadmium and mercury from the body. In humans, methionine is used to produce creatinine required by the brain. People with AIDS have a low level of methionine. Some researchers suggest that this low level methionine in AIDS patients may explain some aspects causing symptoms including dementia [3]. Also, preliminary trials have suggested that methionine may help to treat some symptoms of Parkinson's disease [3].

Chemical, enzymatic and fermentation processes have been used to synthesize amino acids, and the advantage of microbial methods is that the amino acids are purely optically active [4]. Research on possible utilization of the wild strain revealed that many microorganims such as bacteria, yeasts and filamentous fungi accumulates amino acids in culture fluid, but only bacteria have sufficient

\footnotetext{
${ }^{*}$ Competing interests: Authors have declared that no competing interest exists.

"Corresponding author.
}

productivity to warrant the commercial production [5].

Most natural strains cannot produce industrially significant amounts of L-methionine in the culture broth due to various metabolic regulation mechanisms. However, alteration of these mechanisms can lead to L-methionine accumulation [6,7]. The influence of antibiotics and surfactants on amino acid production by bacterial organism has been reported [8-11] although the exact role played by these antibiotics and surfactants are not clearly understood. In our previous work, we reported the production of L-methionine by three methionine yielding strains of Bacillus cereus isolated from different soil ecovars in Owerri, Nigeria [12,13]. The present study, therefore, seeks to investigate the effects of antibiotics and surfactant on methionine accumulation in the culture broth of the three newly isolated Bacillus cereus strains.

\section{Materials and Methods}

\subsection{Microorganisms}

Bacillus cereus DS 13, Bacillus cereus AS 9, Bacillus cereus RS 16 were previously isolated from different soil ecovars in Owerri, Nigera. It was maintained on nutrient agar (Oxoid) slants at $4^{\circ} \mathrm{C}$. The taxonomic identification was done by the method recommended by $[14,15]$. Molecular characterization by 16SrRNA conducted at Macrogen Incoporated Europe confirmed isolates as different strains of Bacillus cereus. 


\subsection{Growth and Cultivation}

The medium for seed culture consist of ( $\mathrm{g} / \mathrm{L}$ ): peptone, 10.0; yeast extract, 10.0; $\mathrm{NaCl}, 5.0$; water, 1 litre, $\mathrm{pH}$ was adjusted to 7.2 with $1 \mathrm{~N} \mathrm{NaOH}$. The medium was sterilized at $121^{\circ} \mathrm{C}$ for 15 minutes. Two loopfuls of a $24 \mathrm{~h}$ slant of the culture was used to inoculate a $250 \mathrm{ml}$ flask containing $50 \mathrm{ml}$ of the seed medium. The flasks were incubated for 16 - $18 \mathrm{~h}$ on a rotary shaker at $120 \mathrm{rpm}$ and $30^{\circ} \mathrm{C}$.

\section{Determination of Growth of the Isolate}

Growth of each isolate was determined turbidimetrically using the culture broth in spectronic 21 spectrophotometer (Camspec, England).

\section{Quantitative Determination of Methionine}

Quantitative determination of L-methionine in the culture broth without purification was carried out by the modified calorimetric method of [16]. A $5 \mathrm{ml}$ volume of the culture broth of each isolate were centrifuged at $5000 \times \mathrm{g}$ for 20 minutes and the cell free supernatant was assayed for L-methionine. $1 \mathrm{ml}$ of $5 \mathrm{~N} \mathrm{NaOH}$ was added to a test tube followed by the addition of $0.1 \mathrm{ml}$ of $10 \%$ sodium nitroprusside solution with through mixing. The mixture was allowed to stand for $10 \mathrm{~min}$. Then two milliliters of $3 \%$ aqueous solution of glycine was added to the reaction mixture with frequent shaking over a period of $10 \mathrm{~min}$. After an additional $10 \mathrm{~min}$ interval, $2 \mathrm{ml}$ of concentrated ortho-phosphoric acid was added drop wise to the mixture with shaking. Colour development was allowed to proceed for $5 \mathrm{~min}$ and the colour intensity measured at $540 \mathrm{~nm}$ in a spectrometer. A blank containing distilled water and all other reagent served as the $100 \%$ transference standard. Results obtained with the test samples were interpolated on a standard methionine curve.

\section{Effect of Antibiotics}

The effects of various concentrations $(0.05-1.0 \mu \mathrm{g} / \mathrm{ml})$ of these antibiotics; tetracycline, ampicillin, erythromycin and chloramphenicol on growth and methionine production was studied. A basal medium consisting of: $\mathrm{KH}_{2} \mathrm{PO}_{4}, 0.5 \mathrm{~g} ; \mathrm{K}_{2} \mathrm{HPO}_{4}, 0.5 \mathrm{~g} ; \mathrm{MgSO}_{4} \cdot 7 \mathrm{H}_{2} \mathrm{O}, 0.001 \mathrm{~g}$; $\mathrm{MnSO}_{4} \cdot 4 \mathrm{H}_{2} \mathrm{O}, 0.001 \mathrm{~g} ; \mathrm{FeSO}_{4} \cdot 7 \mathrm{H}_{2} \mathrm{O}, 0.001 \mathrm{~g} \mathrm{CaCO}_{3}$, 20.0 g; glucose, 80.0 g; $\mathrm{NH}_{4} \mathrm{Cl}_{2}, 20.0$ g for Bacillus cereus DS13, and Bacillus cereus RS 16, glucose, 100.0 g; $\left(\mathrm{NH}_{4}\right)_{2} \mathrm{SO}_{4}, 20.0 \mathrm{~g}$ for Bacillus cereus AS9; distilled water, I litre; pH 7.5 was used. Each antibiotic solution was added to the sterilized fermentation medium and fermentation process carried out for $72 \mathrm{~h}$ and $30^{\circ} \mathrm{C}$ on a rotary shaker at $170 \mathrm{rpm}$. Growth and methionine production was determined as previously described.

\section{Effect of Surfactant}

The effects of various concentrations $(0.1-1.0 \mathrm{v} / \mathrm{v})$ of tween 80, oleic acid, linoleic acid, and $(0.05-1.0 \mu \mathrm{g} / \mathrm{ml})$ of palmitic and stearic acids on growth and methionine production were examined. A basal medium consisting of; $\mathrm{KH}_{2} \mathrm{PO}_{4}, 0.5 \mathrm{~g} ; \mathrm{K}_{2} \mathrm{HPO}_{4}, 0.5 \mathrm{~g} ; \mathrm{MgSO}_{4} \cdot 7 \mathrm{H}_{2} \mathrm{O}, 0.001$ g; $\mathrm{MnSO}_{4} \cdot 4 \mathrm{H}_{2} \mathrm{O}, 0.001 \mathrm{~g} ; \mathrm{FeSO}_{4} \cdot 7 \mathrm{H}_{2} \mathrm{O}, 0.001 \mathrm{~g} \mathrm{CaCO}$, 20.0 g; glucose, 80.0 g; $\mathrm{NH}_{4} \mathrm{Cl}_{2}, 20.0$ g for Bacillus cereus DS13, and Bacillus cereus RS 16, glucose, 100.0 g; $\left(\mathrm{NH}_{4}\right)_{2} \mathrm{SO}_{4}, 20.0 \mathrm{~g}$ for Bacillus cereus AS9; distilled water, I litre; $\mathrm{pH} 7.5$ was used. Fermentation was carried out for $72 \mathrm{~h}$ at $30^{\circ} \mathrm{C}$ on a rotary shaker at $170 \mathrm{rpm}$. Growth and methionine concentration was determined at the end of fermentation period. All experiments were conducted in triplicates with uninoculated flasks as control.

\section{Results and Discussion}

Studies on the effect of antibiotics on growth and methionine productivity shown in Figures 1-3, reveals that tetracycline and chloramphenicol at 0.05 and $0.1 \mu \mathrm{g} / \mathrm{ml}$ enhanced methionine productivity but did not stimulate

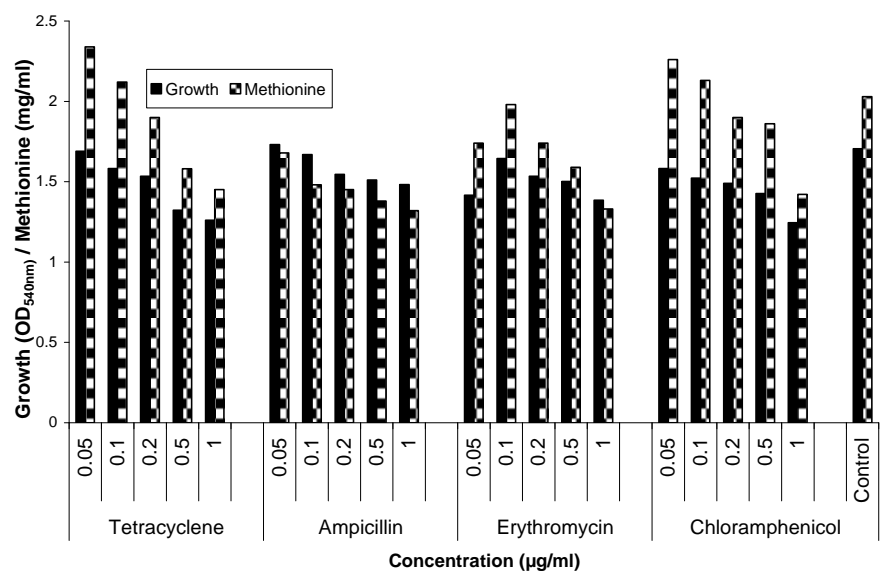

Figure 1. Effect of different concentrations of antibiotics on growth and methionine production by Bacillus cereus DS13. 


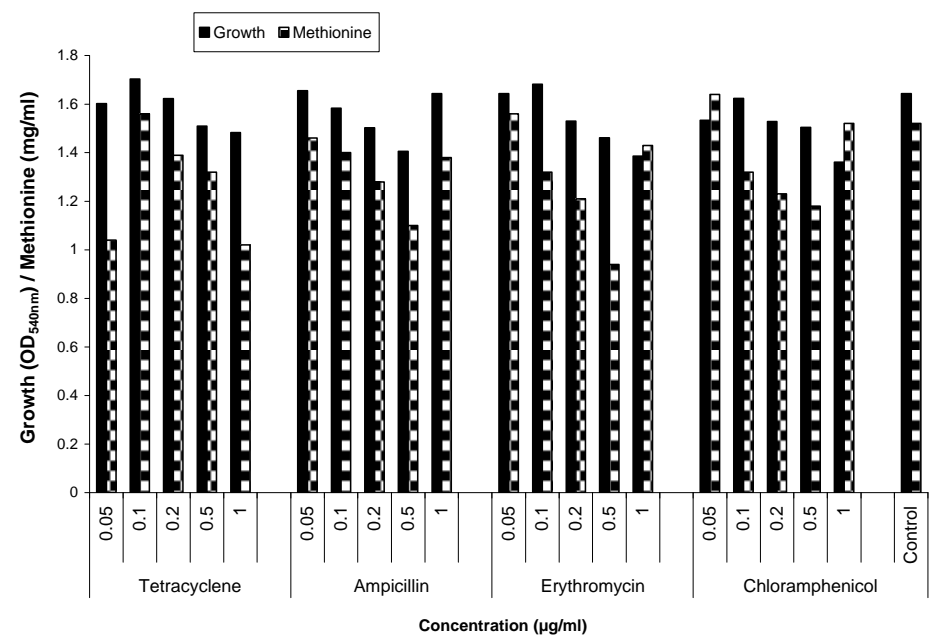

Figure 2. Effect of different concentration of antibioitics on growth and methionine production by Bacillus cereus AS9.

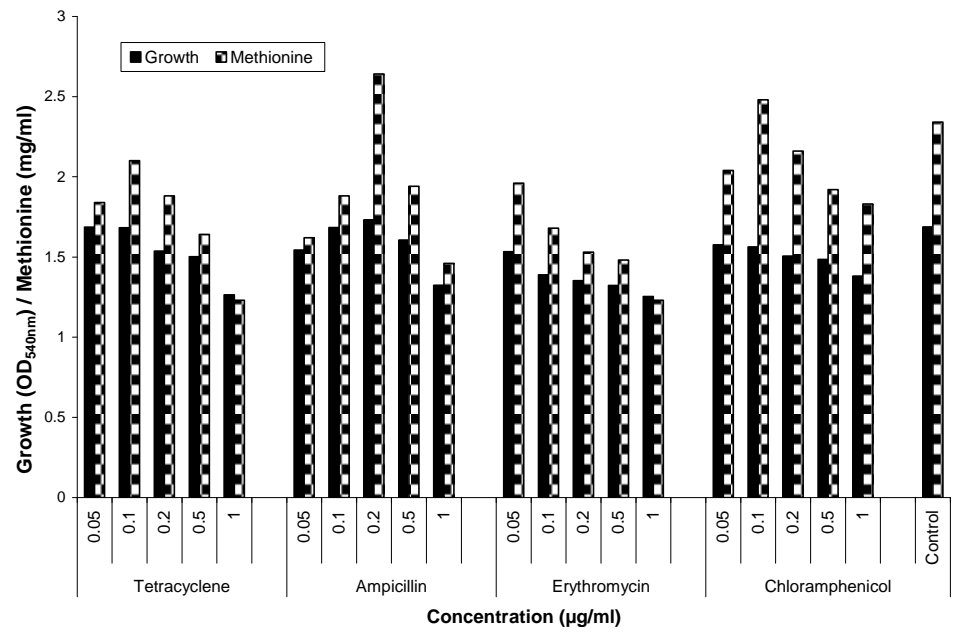

Figure 3. Effect of different concentration of antibiotics on growth and methionine by Bacillus cereus RS16.

growth in broth culture of Bacillus cereus DS 13. Ampicillin and erythromycin at all concentrations did not enhance methionine yield. In the result shown in Figure 2 , tetracycline at $0.10 \mu \mathrm{g} / \mathrm{ml}$ and chloramphenicol at 0.05 $\mu \mathrm{g} / \mathrm{ml}$ improved methionine yield in broth culture of $\mathrm{Ba}$ cillus cereus AS 9, while ampicillin at $0.20 \mu \mathrm{g} / \mathrm{ml}$ and chloramphenicol at $0.1 \mu \mathrm{g} / \mathrm{ml}$ stimulated methionine yield in broth culture of Bacillus cereus RS16 (Figure 3). There are no reports on the effect of antibiotics on methionine production. [9,17] have reported increased amino acid production in the presence of small quantities of several kinds of antibiotics, although the exact role played by these antibiotics is not clearly understood. [18] suggested that a change in permeability of the cell wall caused by antibiotics may be responsible for improved yield. This change in permeability affects the intracellular accumulation of amino acids resulting in the inability of the amino acid to regulate its own synthesis by feedback control, thereby releasing high levels of amino acid into the medium. The stimulatory effect of tetracycline reported in this work is supported by the work of [19]. They reported an increase in lysine yield by Micrococcus glutamicus when the antibiotic was added to the fermentation culture.

Surfactants are well known surface agents that are generally used to improve the surface area for microbial action and availability of nutrients to the microorganisms. Results (Figures 4-6) indicates that tween 80 (at 0.5 and $1.0 \mu \mathrm{g} / \mathrm{ml}$ ) and palmitic acid at all concentration except $0.05 \mu \mathrm{g} / \mathrm{ml}$ enhanced methionine accumulation in broth culture of $B$. cereus DS13 while oleic acid, linoleic acid and stearic acid did not stimulate methionine production. Growth of B. cereus DS13 was enhanced with the addition of stearic acid at all concentration. This agrees with the work of [20] who reported a stimulatory effect of tween 80 on lysine production by Bacillus megaterium. [8,11] observed a stimulatory effect on lysine production by Corynebacterium glutamicum with definite concentrations 


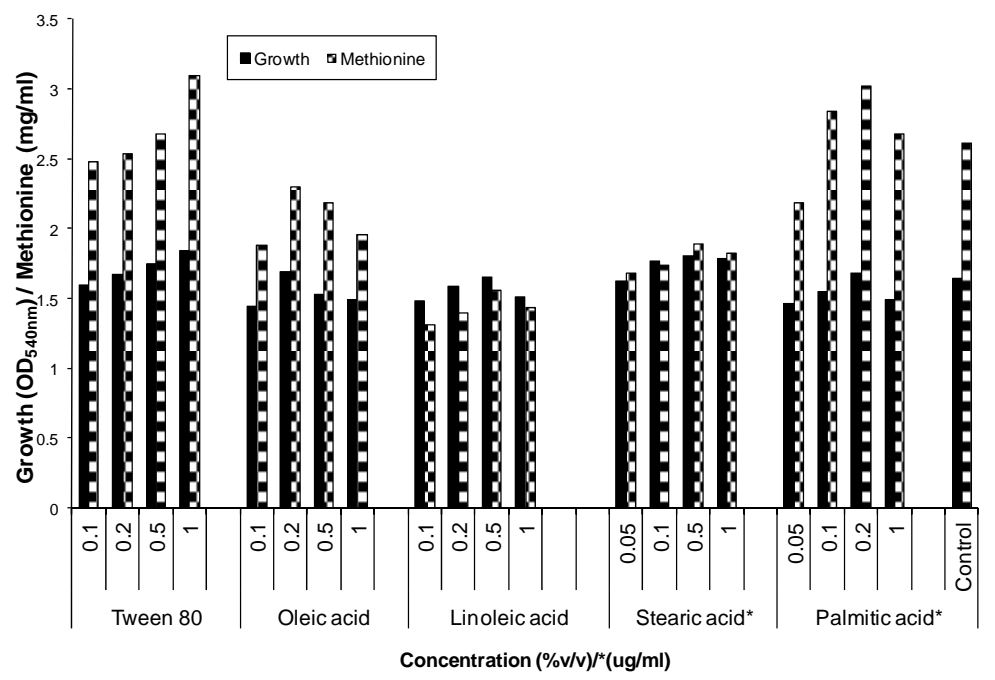

Figure 4. Effect of different concentration of surfactants on growth and methionine production by Bacillus cereus DS13.

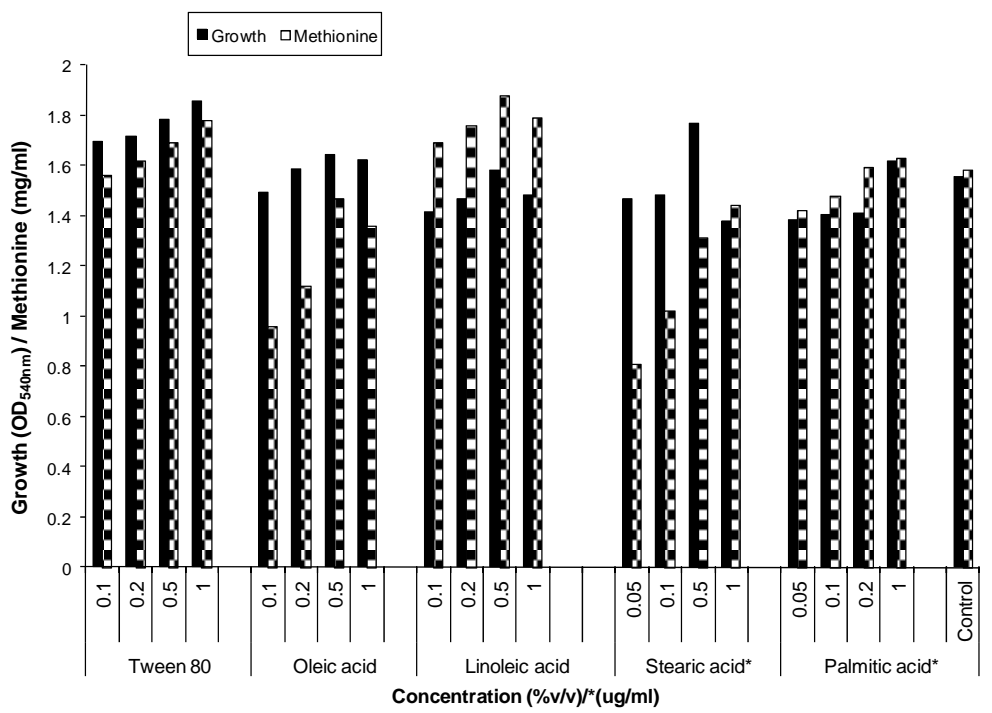

Figure 5. Effect of different concentration of surfactants on growth and methionine production by Bacillus cereus AS9.

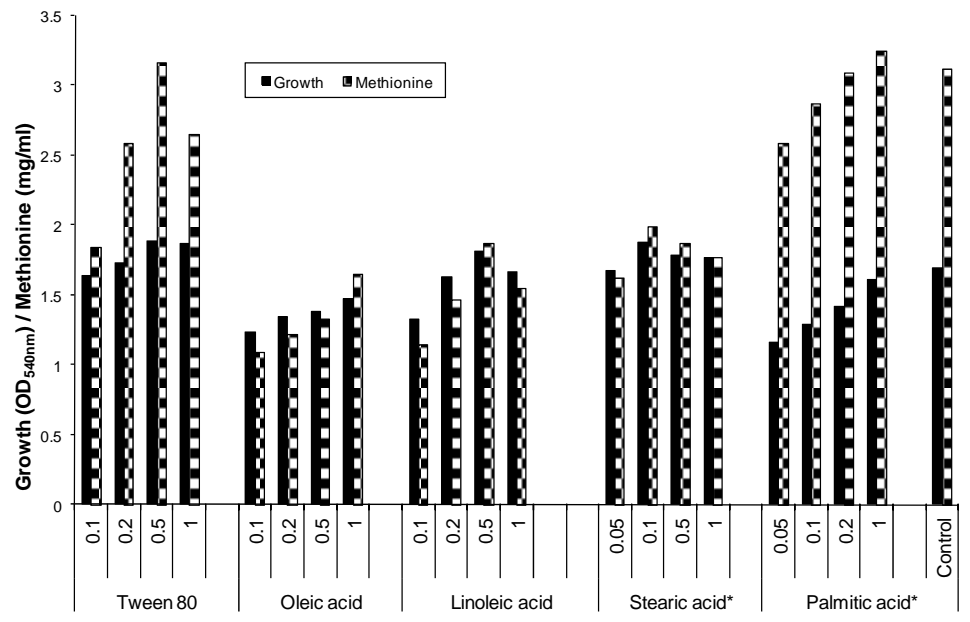

Figure 6. Effect of different concentration of surfactants on growth and methionine production by Bacillus cereus RS16. 
of liquid tween 80 . According to [11,21,22] surfactants stimulate biodegradation of nutrients by increasing the solubility and dispersion of the compounds thus enhancing the release of metabolites into the medium by cell rupturing after its production. These results however, contrasts the work of [23] who reported a non stimulatory effect of tween 80 on production of methionine and glutamic acid by Serratia marcescens var kiliensis. Unsaturated fatty acids; linoleic acid enhanced methionine accumulation in the broth culture of Bacillus cereus AS 9 while oleic acid stimulated growth and improved methionine production in broth culture of Bacillus cereus DS13. There are no reports on the effect of fatty acids on the production of methionine. [20] however reported a stimulatory effect of linoleic acid on lysine production by Bacillus megaterium. [23] reported the growth promoting effect of unsaturated fatty acids in Lactobacillus casei. They observed that lowering the fatty acid concentration beneath a critical level or prolonging the period of incubation, resulted in growth stimulation. The saturated fatty acid; palmitic acid stimulated growth and improved methionine yield in all Bacillus strains. Stearic acid on the other hand enhanced growth in all Bacillus strains but did not stimulate methionine yield. The growth promoting effect of the saturated fatty acids reported in this work is in line with the works of [24] who reported a stimulating effect of saturated fatty acids on L-glutamic acid producing bacteria. [25] observed that long chain fatty acids such as lauric acid, stearic acid and oleic acid did not stimulate lysine production in Brevibacterium lactofermentum.

[26] have found that inhibitory effects of long chain fatty acid on cell wall digestibility is inversely related to their ability to form insoluble calcium soaps, thus the relative inhibitory effects of the different fatty acids may be partially explained by their selective removal from the medium as insoluble soaps. [27] on their work on L-glutamic acid producing bacteria, noted that C16 to C18 saturated fatty acids-treated in the absence of biotin synthesized insufficient amounts of phospholipids on the cell membrane, thus resulting in enhanced permeability towards L-glutamic acid. It may be possible to suggest that improved methionine accumulation observed in $B$. cereus DS 13 and $B$. cereus RS16 were due to similar permeability process. This experimental study has shown that antibiotics and surfactants stimulated methionine yields in Bacillus cereus even though they are strain dependent.

\section{Acknowledgements}

The authors are very grateful to Marian Figge of the Netherlands culture collection of bacteria (NCCB) for her assistance in the purchase of the E. coli auxotrophs used for this work. We are also thankful to Macrogen Incoporated South Korea for accepting to do the molecular cha- racterization at a very affordable price.

\section{REFERENCES}

[1] J. George, N. Pera, N. Phung, I. Leclercq, J. Y. Hou and G. Farrell, "Lipid Peroxidation, Stellate Cell Activation and Hepatic Fibrogenesis in a Rat Model of Chronic Steatohepatitis,” Journal of Hepatology, Vol. 39, No. 5, 2003, pp. 756-764. doi:10.1016/S0168-8278(03)00376-3

[2] K. K. Carroll and E. M. Kurowska, "Soy Consumption and Cholesterol Reduction: Review of Animal and Human Studies,” Journal of Nutrition, Vol. 125, No. 3, 1999, pp. 594S-597S.

[3] D. M. Townsend, K. D. Tew and H. Tapiero, "Sulfur Containing Amino Acids and Human Disease," Biomedical Pharmacology, Vol. 58, No. 1, 2004, pp. 47-55. doi:10.1016/j.biopha.2003.11.005

[4] S. Kinoshita, S. Udaka and M. Shimono, "Amino Acid Fermentation. Production of L-Glutamic Acid by Various Microorganisms," Journal of General Applied Microbiology, Vol. 3, No. 7, 1957, pp. 193-205. doi:10.2323/igam.3.193

[5] K. Soda, H. Tanaka and N. Esaki, “Amino Acids,” In: H. J. Rehm and G. Reed, Eds., Biotechnology, Pergamon Press, Oxford, 1983, pp. 479-530.

[6] H. Kase and K. Nakayama, "O-Acetylhomoserine as an Intermediate in Methionine Biosynthesis in Arthrobacter paraffineus, Corynebacterium glutamicum and Bacillus Species," Agriculture and Biological Chemistry, Vol. 39, No. 3, 1975, pp. 687-693. doi:10.1271/bbb1961.39.687

[7] M. K. Chattopadhyay, D. Sengupta and S. Sengupta, "Fermentative Production of Methionine by 5-Bromouracil Resistant Mutants of Escherichia coli K-12," Medica Science Research, Vol. 23, No. 23, 1995, pp. 775-776.

[8] F. Smekal, V. Bulant, E. Kindlova, M. Mazalova and S. Ulbert, "Production of L-Lysine Using Non-Standard Nitrogen Sources,” Kvansy Prum, Vol. 28, No. 3, 1982, pp. 9-40.

[9] K. S. Sen and S. P. Chatterjee, "Influence of B-Vitamins and Trace Elements on Lysine Production by Micrococcus varians 2fa," Acta Biotechnology, Vol. 9, No. 1, 1986, pp. 63-67. doi:10.1002/abio.370090111

[10] C. J. Israilides, A. N. Weir and A. T. Bull, "Effect of Antibiotic on Lysine Production in Free and Immobilized Cells of Bacillus subtilis,” Applied Microbiology and Biotechnology, Vol. 32, No. 2, 1986, pp. 134-136. doi:10.1007/BF00165876

[11] J. Konicek, F. Smekal and M. Konickova-Radochora, "Ef fect of tween 80 and Dimethyl Sulfoxide on Biosynthesis of Lysine in Regulatory Mutants of Corynebacterium glutamicum," Folia Microbiology, Vol. 36, No. 6, 1991, pp. 587-589. doi:10.1007/BF02884043

[12] K. S. Dike and I. A. Ekwealor, "Production of L-Methionine by Bacillus cereus Isolated from Different Soil Ecovars in Owerri, South East Nigeria,” European Journal of Experimental Biology, Vol. 2, No. 2, 2012, pp. 311-314.

[13] K. S. Dike and I. A. Ekwealor, "Studies on Process and 
Physical Parameters for the Production of L-Methionine from Newly Isolated Bacillus cereus Strains,” Asian Journal of Biological Sciences, Vol. 5, No. 2, 2012, pp. 96104. doi:10.3923/ajbs.2012.96.104

[14] G. I. Barrow and A. K. R Felthan, "Cowan and Steel's Manual for the Identification of Medical Bacteria,” 3rd Edition, Cambridge University Press, Cambridge, 1993.

[15] R. E. Buchanan and N. E. Gibbon, "Bergey's Manual of Determinative Bacteriology," 8th Edition, Williams and Wilkins Co., Baltimore, 1974.

[16] J. P. Greenstein and M. W. Methionine, "Chemistry of the Amino Acid,” John Wiley \& Sons, Chichester, 1961.

[17] K. Yamada, S. Kinoshita, T. Tsunoda and K. Aida, "The Microbial Production of Amino Acids,” John Wiley and sons, New York, 1972.

[18] A. L. Demain and J. Birnbaum, "Alteration of Permeability for the Release of Metabolites from the Microbial Cell," Current Topics in Microbiology, Vol. 46, No. 2, 1968, pp. 1-26.

[19] D. Zaki, O. Galal, A. S. Hazino-Wahba, I. K. Morsi and A. E. Wakell, "Microbiological Production of Lysine," Nutritional Research International, Vol. 26, No. 26, 1982, pp. 537-546.

[20] A. I. Ekwealor and J. A. N. Obetan, "Antibiotic and Surfactant Effects of Lysine Accumulation by Bacillus megaterium," African Journal of Biotechnology, Vol. 7, No. 10, 2008, pp. 1550-1553.

[21] J. D. Desai and I. M Banat, "Microbial Production of Surfactants and Their Commercial Potential," Microbiology and Molecular Biology Review, Vol. 61, No. 1, 1997, pp.
47-64.

[22] Q. Helmy, P. E. Suryatmana, V. Kardena and F. Wisjnuprapto, "Effect of Surfactant Addition on Oil Sludge Biodegradation by Petrofilic Bacteria,” The 3rd International Conference on Environmental Technology and Management, Bandung-Indonesia, October 2006, pp. 1-5.

[23] B. B. Ghosh and A. K Banerjee, "Production of Methionine and Glutamic Acid from n-Alkanes by Serratia marcescens Var. kiliensis,” Folia Microbiology, Vol. 31, No. 2, 1986, pp. 106-112. doi:10.1007/BF02926827

[24] V. R. William and E. A. Fieger, "Further Studies on Lipid Stimulation of Lactobacillus casei,” Journal of Biological Chemistry, Vol. 177, No. 2, 1949, pp. 739-744.

[25] O. Tosaka, Y. Yoshihara, S. Ikeda and K. Takinami, "Production of L-Lysine Fluoropyruvate Sensitive Mutants of Brevibacterium lactofermentum," Agriculture and Biological Chemistry, Vol. 49, No. 5, 1985, pp. 1305-1312. doi:10.1271/bbb1961.49.1305

[26] H. Galbraith, T. B. Miller, A. M. Paton and J. K. Thompson, "Antibacterial Activity of Long Chain Fatty Acids and the Reversal with Calcium, Magnesium, Ergocalciferol and Cholesterol,” Journal of Applied Bacteriology, Vol. 34, No. 4, 1975, pp. 803-813.

[27] K. Takinami, O. Okada and T. Tsunoda, "Biochemical Effects of Fatty Acid and Its Derivatives on L-Glutamic Acid Fermentation I. Accumulation of L-Gluatamic Acid in the Presence of Sucrose Fatty Acid Ester,” Agriculture and Biological Chemistry, Vol. 27, No. 2, 1963, pp. 858863. 